\title{
Micrometeorological Parameter and Energy Balance over Soybean
}

\author{
A. Khan, B. S. Nahar, M. M. Hossain, and M. A. Baten \\ Department of Environmental Science, Bangladesh Agricultural University, Mymensingh
}

\begin{abstract}
An experiment was conducted at the Environmental Science Field Laboratory, Bangladesh Agricultural University, Mymensingh, to investigate the micrometeorological parameters such as air temperature, relative humidity, soil temperature, light intensity, solar radiation, photosynthetic active radiation (PAR), albedo and energy balance components over soybean field. Air temperature, solar radiation, light intensity were lower at the early morning hours, which gradually increased with the advancement of time and peaked at 13:00 hours, immediate after13:00 hours those value gradually declined. On the other hand air temperature and relative humidity were negatively correlated i.e. with the increase of air temperature, the relative humidity decreased. Soil temperature were measured at 2,5 and $10 \mathrm{~cm}$ depth and found that there was a distinct variation between 2 and 10 $\mathrm{cm}$ depth. Whereas, there was a small variation between 5 and $10 \mathrm{~cm}$ depth. Albedo level range from 0.18 to 0.24 and average value was 0.21 at midday. The energy balance components were measured using Bowen Ratio Energy Balance (BREB) method. On an average latent heat flux (LE) was 69 to $93 \%$ and ground heat flux (G) was 7 to $29 \%$ of the total Rn. Sensible heat flux (H) showed the negligible values due to wet soil surface and high soil moisture.
\end{abstract}

Key Words: Micrometeorology, Soybean

\section{Introduction}

Soybean, a well recognized oil and protein rich crop of the world, can play a vital role for substantial production of the country. As a legume, it can also help to keep soil health naturally balanced by reducing the use of chemical fertilizer. Attention should be made for increasing the yield per unit area by manipulating micrometeorological parameters and by computing energy balance components of soybean field.

Micrometeorology deals with the exchange of heat (energy), mass and momentum occurring continuously between the atmosphere and the earth's surface, including the surface medium. The energy budget at or near the surface on a short -term basis is an important aspect of the different types of energy exchanges involved in the earth atmosphere-sun system. Proper manipulation of microclimate can improve the growth and yield of crops (Kler et al., 1992)

Energy balance component is an important factor for increasing yield in different field crops (Chin Choy and Kanemasu, 1974). The energy balance shows net radiation is partitioned into different components for the purpose of transpiration, evapotranspiration (ET), advective energy movement and ground heat storage. Several prior studies on energy fluxes in a single community reported the influence of Micrometeorology (e.g. solar radiation, wind speed, air and soil temperature, vapor pressure deficit, albedo etc.) and biological factors (leaf area, stomatal conductance, plant height, species composition and development) on ET. (Anderson and Idso, 1987; Rao, 1988; Hammer,1989; Parkhurst., et al., 1998).
Soil temperature is an important factor influencing the crop yield. For soybean, a soil temperature of $15.6^{\circ} \mathrm{C}$ or above promotes rapid germination and vigorous seedling growth. High temperature above $32.2^{\circ} \mathrm{C}$ reduces yield and lower oil quality, temperatures below $21.1^{\circ} \mathrm{C}$ delay flowering. The minimum temperature for effective growth is about $10^{\circ} \mathrm{C}$ (Chapman and Carte, 1976).

Solar radiation is the primary energy source for crop production. Leaf number increases in narrow spacing. So, soil temperature was found high in wide spacing compared to narrow spacing due to larger penetrated solar radiation on it ( Baten ang Kon , 1997). The canopy temperature in narrow spacing is high due to maximum solar radiation interception. Greater light interception during the vegetative and reproductive stages enhance yield of soybean (Schou et al., 1978) .

Penetration of global radiation and net radiation is found to vary with row orientation and cropping seasons (Baten and Kon, 1997). At low solar elevation angles on $35^{\circ} 46^{\prime} \mathrm{N}$ latitude, penetration of solar radiation is larger at the soil surface between N$\mathrm{S}$ row spaces than that of E-W rows (Baten and Kon, 1997) and thus the rate of evaporation at N-S row space must be different from that of E-W row spaces. On the contrary, E-W row canopy intercept larger solar radiation as compared to N-S row canopy during low solar elevation angles (Baten and Kon, 1997) and thus the rate of transpiration of E-W row canopy must be different from the N-S row canopy. 
Considering the above facts the present's research work was undertaken with the following objectives:

i. To investigate a few micrometeorological parameters

ii. To evaluate the energy balance components over soybean field

$$
\text { i.e. } R n=H+L E+G
$$

\section{Materials and Methods}

Investigation of micrometeorological parameters and energy balance components over soybean was carried out at the field laboratory of the Department of Environmental Science, Bangladesh Agricultural University, Mymensingh. In this chapter, the details of different materials used and methodologies followed during the experimental period are described under the following heads.

\section{Experimental details:}

The experimental plot was laid out with one replication. The plot size was $20 \mathrm{~m} * 20 \mathrm{~m}$ E-W direction. Plant to plant distance was $10 \mathrm{~cm}$ and row to row distance was $50 \mathrm{~cm}$.

\section{Measurement Elements and Methods of Measurement \\ Micrometeorological elements such as air temperature, relative humidity, net radiation, incoming and reflected solar radiation, photosynthetic active radiation (PAR), soil heat flux, soil temperature, the number of sensors and their settings location are described below.}

\section{Vaisala sensor}

To measure air temperature and relative humidity at different level Viasala sensor was used. The Viasala sensor (HMP45D, Finland) were placed at three different heights from the soil surface. The first placed at $120 \mathrm{~cm}$ and third sensor was placed at $200 \mathrm{~cm}$ height from the soil surface.

\section{Pyranometer}

Three pyranometers (K91025 Japan; K91026 Japan and K91016 Japan) were used to measure incoming solar radiation over and below the canopy (at soil surface) and reflected solar radiation. Pyranometer K91026 Japan was set at soil surface, Pyranometer K91025 Japan was set above $180 \mathrm{~cm}$ from soil surface to measure penetrated and global solar radiation and Pyranometer K91016 Japan was set at $180 \mathrm{~cm}$ height to obtain reflected solar radiation (albedo).

\section{Ground Heat Flux Plate}

Ground Heat Flux (G) was measured by ground heat flow plate. Ground Heat Flux plates (EKO,MF81, Japan) were placed horizontally at $1 \mathrm{~cm}$ depth from the ground surface and covered with the soil to guarantee the measuring accuracy.

\section{Thermocouple Thermometers}

Three thermocouples with different height such as 2 $\mathrm{cm}, 5 \mathrm{~cm}$ and $10 \mathrm{~cm}$ depth were set on a bamboo stick horizontally and then the each bamboo stick was vertically placed on soil. After placing the Thermocouples, water was supplied to connect it tightly with the soil. Data from all sensors were recorded automatically in the CR1OX data logger with the help of 25T multiplexer (Campbenn Scientific, USA) which was placed on a tin made small house.

\section{Plant Height and Canopy Width and Leaf Area}

Plant height and canopy width were measured three times during the study period with a measuring scale. Leaf area was measured with a digital leaf area meter from central laboratory, Bangladesh Agricultural University, Mymensingh, to evaluate the leaf area index.

\section{Measurement of Energy Balance Components}

By using the following formula, canopy energy balance can be calculated (Ham et al.1991)

Where,

$$
R n=H+L E+G
$$

$$
\begin{aligned}
& \mathrm{Rn}=\text { Canopy net radiation }\left(\mathrm{Wm}^{-2}\right) \\
& \mathrm{H}=\text { Sensible heat flux }\left(\mathrm{Wm}^{-2}\right) \\
& \mathrm{LE}=\text { Latent heat flux }\left(\mathrm{Wm}^{-2}\right) \\
& \mathrm{G}=\text { Ground heat flux }\left(\mathrm{Wm}^{-2}\right)
\end{aligned}
$$

\section{Sensible Heat Flux}

Sensible Heat Flux $(\mathrm{H})$ from the soybean field (soil + soybean canopy) was calculated from Bowen Ratio Energy Balance (BREB) method using the following formula:

$$
\bar{H}=\frac{R_{n}-G}{1+\beta^{-1}}
$$

\section{Latent Heat Flux}

Latent Heat Flux from the soybean field (soil + soybean canopy) was calculated from Bowen Ratio Energy Balance (BREB) method using the following formula:

$$
l E=\frac{R_{n}-G}{1+\beta}
$$




\section{Result and Discussion}

Observation of micrometeorology parameters such as such as air temperature, relative humidity, soil temperature, light intensity, solar radiation, albedo, energy balance components such as net radiation $(R n)$, latent heat flux $(L E)$,sensible heat flux $(H)$, and soil heat flux $(G)$ that observed over soybean field have been presented and discussed in this chapter. Plant height, canopy width and leaf area index are shown in Table 1.

Table 1. Height, width and LAI of soybean canopy of E-W orientation during the study period.

\begin{tabular}{|c|c|c|c|}
\hline DAYS & Plant Height $(\mathrm{cm})$ & Canopy Width $(\mathrm{cm})$ & LAI $\left(\mathrm{m}^{2} \mathrm{~m}^{-2}\right)$ \\
\hline 59 & 52.15 & 34.92 & 4.97 \\
60 & 52.55 & 35.16 & 4.98 \\
61 & 53.05 & 35.85 & 5.10 \\
62 & 53.65 & 36.37 & 5.10 \\
65 & 55.57 & 37.14 & 5.56 \\
70 & 60.09 & 38.90 & 5.82 \\
71 & 60.66 & 39.25 & 5.90 \\
\hline
\end{tabular}

\section{Micrometeorological parameters}

The micrometeorological parameters that were observed over the soybean field are described here one after another.

\section{Air temperature}

Air temperature was measured during 62 DOY to 69 DOY and 73 DOY to 74 DOY, 2005 over soybean field and is presented in fig 1 . Fig 1 clearly indicate that air temperature was lower (about $20^{\circ} \mathrm{C}$ ) at the early morning hours which gradually increased with the advantage of day time. The highest temperature (about 32 to $33^{\circ} \mathrm{C}$ ) was found from the time range 13:00 to $13: 30$ hours. But after 13:30 hours the air temperature gradually declined. The latent heat flux from the canopy might be more sensitive to air temperature than that of latent heat flux from the soil, where soybean crops grown in well-watered condition with N-S row (Sakuratani, 1987).

\section{Relative Humidity}

Relative humidity as measured with air temperature at the same a DOY over the soybean field which is indicate in the fig 2. From the figure, it was found higher relative humidity in the early morning hours that gradually decreased with increase of daytime. The lowest relative humidity was 30 to $31 \%$ at 13:00 hours. After 13:00 hours, the relative humidity increased gradually with the advancement of time.

Fig 1 and Fig 2 clearly demonstrated that at the same time, air temperature and relative humidity were negatively correlated. Results indicated that humidity was decreased with the increase of air temperature. Negative correlation also found between relative humidity and penetration of solar radiation. On the other hand, air temperature and solar penetration was positively correlated with each other. Best negative correlation was reported by Szlovak et al. (1992).

\section{Soil Temperature}

The measurement of soil temperature is graphically presented in the fig 3 at different sol depth $(2,5$ and $10 \mathrm{~cm}$, respectively).The fig showed the maximum soil temperature attained at the time of maximum insulation, while minimum temperature reached in early morning hours and in the evening. There was distinct variation with variation of soil depth among the temperature of the sensors. About 7 to 29 of $R n$ is accounted for soil heat flux (Table 2), very little heat was transferred into the soil. Between 5 to $10 \mathrm{~cm}$ soil depths, there was a small variation in temperature. However, between 2 and $10 \mathrm{~cm}$ depth distinct variation of soil temperature was found from the fig 3 .

\section{Solar Radiation}

The solar radiation components over soybean were measured from the Julian day 62 to 65,69 and 73 to 75 which were shown in the fig 4 . Fig 4 shows that the global solar radiation was increased with the increase of day time and decreased in the afternoon and evening. At the time ranging 12:00 to $12: 30$ hours the global radiation is maximum which was $946 \mathrm{Wm}^{-2}$. Ham et al. (1991) reported that solar radiation penetration increased rapidly at nearly 9:00 hours to till noon.

\section{Energy Balance Relationship}

Energy balance relationship of soybean canopy in day time with the ratios of latent, sensible and soil heat fluxes to net radiation is presented in table 2 .

Latent heat flux accounted for a large portion of $R n$ as it was expected from the sufficient soil water content. Frischen and Van Bavel (1962) reported that, in most soil condition almost all energy supplied by $R n$ isconsumed as latent heat. 
Average latent heat flux density during study period was $9.34 \mathrm{MJm}^{-2}$ day $^{-1}$. On an average, $L E$ was 69 to93\%, $H$ was 1 to $2 \%$ and $G$ was 7 to $29 \%$ of whole $R n$.

$\mathrm{H}$ showed negligible values indicating absorption of the sensible heat by the wet soil from the upper air, which provided energy for $L E$. In E-W soybean rows
$\mathrm{H}$ was 2 to $7 \%$ of $R n$ and in N-S soybean rows it was 1 to $10 \%$ of $R n$ (Baten et al., 1997). Ham et al. (1991) reported that 8 to 21 of $R n$ partitioned to $H$ for N-S cotton rows. Baten et al. (1997) also reported that 14 to $18 \%$ of $R n$ partitioned to $G$ for E-W soybean rows and 6 to $9 \%$ of $R n$ partitioned to $G$ for N-S soybean rows.

Table 2. Daytime (6:00 to 18:00h) energy balance components with ratio of latent and soil heat fluxes to net radiation

\begin{tabular}{|c|c|c|c|c|c|c|c|}
\hline Julian Day & Rn & $\begin{array}{c}L E \\
m^{-2} d a y\end{array}$ & ---- & $G$ & $L E / R n$ & $H / R n$ & $G / R n$ \\
\hline 62 & 9.07 & 6.30 & 0.11 & 2.67 & 0.69 & 0.01 & 0.29 \\
\hline 63 & 10.49 & 8.81 & 0.26 & 2.06 & 0.78 & 0.02 & 0.20 \\
\hline 64 & 9.42 & 7.55 & 0.12 & 1.75 & 0.80 & 0.01 & 0.19 \\
\hline 65 & 9.68 & 8.35 & 0.06 & 1.28 & 0.86 & 0.01 & 0.13 \\
\hline 69 & 12.95 & 11.40 & 0.26 & 1.28 & 0.88 & 0.02 & 0.10 \\
\hline 73 & 13.65 & 12.76 & 0.07 & 0.89 & 0.93 & 0.01 & 0.07 \\
\hline 74 & 11.68 & 10.85 & 0.06 & 0.77 & 0.93 & 0.01 & 0.07 \\
\hline Average & 10.99 & 9.34 & 0.13 & 1.53 & 0.84 & 0.01 & 0.15 \\
\hline
\end{tabular}

** $R n=$ Net radiation over the plot; $L E=$ Latent heat flux from the canopy; $H=$ Sensible heat flux from the canopy; $G=$ Ground heat flux

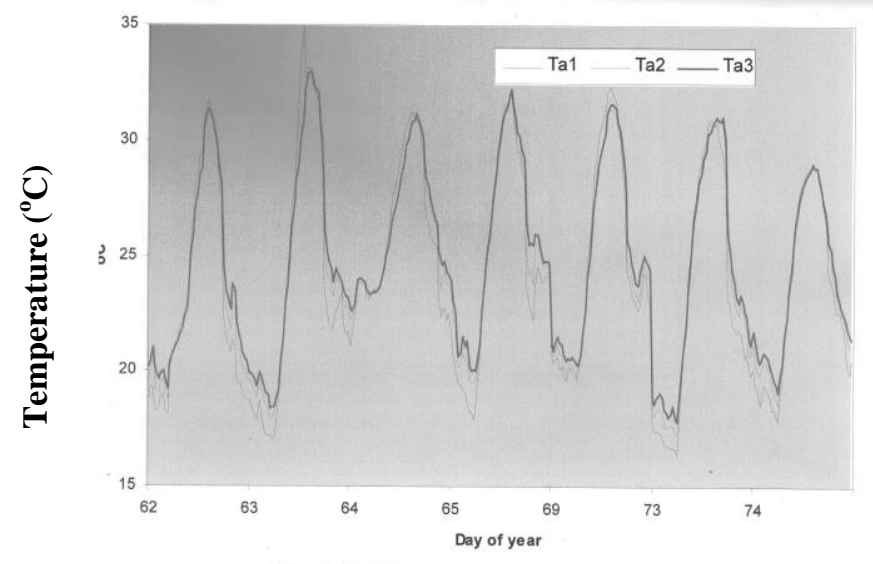

Fig. 1 Air Temperature over Soybean field

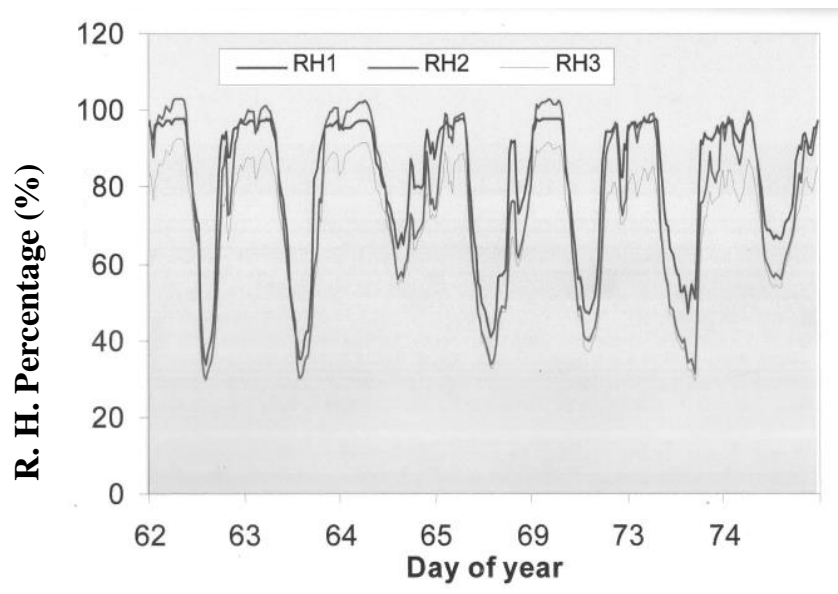

Fig. 2 Relative Humidity over Soybean 

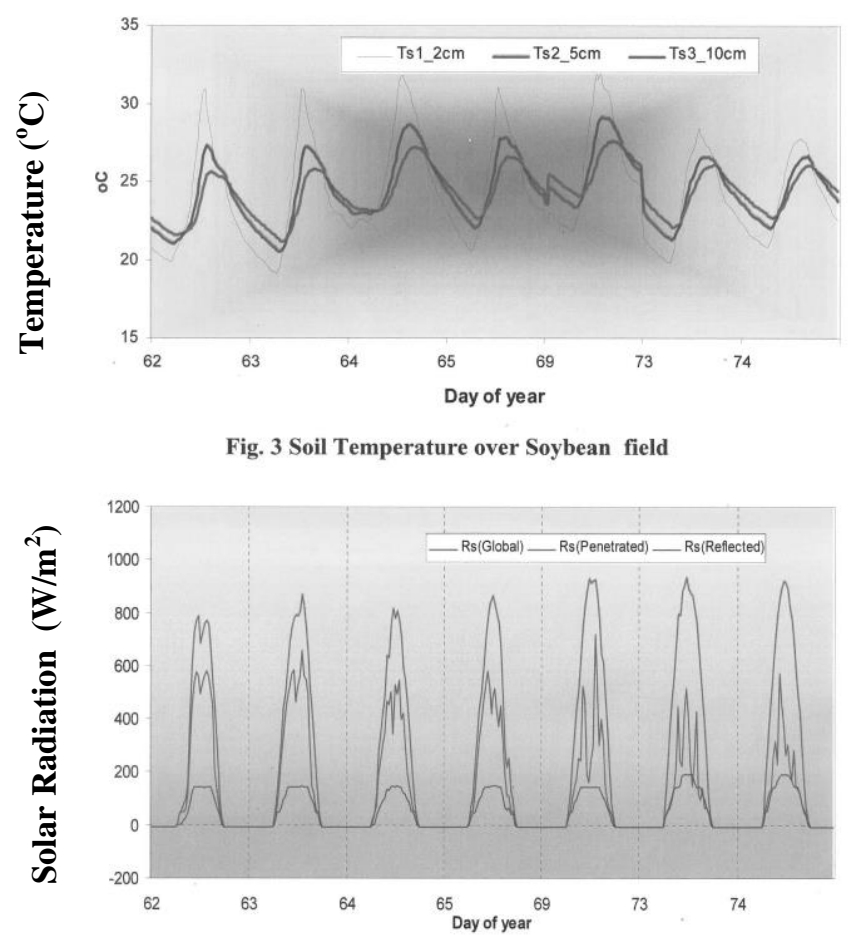

Fig. 4 Solar Radiation components over Soybean field

\section{Conclusion}

An experiment was carried out at the Environmental Science Field Laboratory, Bangladesh Agricultural University, Mymensingh, with a view to investigate some selected micrometeorology parameters over soybean. Air temperature, relative humidity, soil temperature, at different heights as well as, solar radiation,, energy balance components such as net radiation $(R n)$, latent heat flux $(L E)$, sensible heat flux $(H)$, and soil heat flux $(G)$ were measured during the experimental period using sophisticated modern sensors.

Air temperature(Ta), Soil temperature (Ts), solar radiation(Rs) components showed minimum values in the early morning hours which gradually increased with the advancement of time and peaked at 13:00 hours, the relative humidity (Rs) was highest in the early morning and late afternoon which gradually decreased with the advancement of time and it was lowest at 13:00 hours.

The energy balance components were measured using Bowen Ratio Energy Balance (BREB) method. Net Radiation $(R n)$, soil heat flux $(G)$ obtained directly from the net radiometer and ground heat flux $(L E)$ were calculated from BREB, method. The average $L E, G$ and $H$ were $69-93 \%, 7-29 \%$ and $1-2 \%$ respectively of total $R n$. The average $L E / R n, G / R n$ and $H / R n$ were $0.84,0.15$ and 0.01 respectively.

Air temperature, relative humidity, soil temperature, light intensity, solar radiation, PAR and albedo could influence evaporation, water content of soil. Transpiration, photosynthesis and growth of crop plants. Therefore, these kinds of data would be helpful for better irrigation scheduling and better management of crop. For better understanding of energy balance could help research in crop biophysics, soil physics, climate change and agroecosystem modeling. Attempt should be made in future to find out the way of study of the effective micrometeorological research for various canopies with simulation model studies.

\section{References}

Anderson, M.G. and Idso, S.B. 1987. Surface geometry and stomatal conductance effects on evaporation from aquatic macrophytes. Water Res., 23: 1037-1042. 
Baten, M.A. and Kon, H. 1997. Comparisons of solar radiation interception albedo and net radiation as influenced by row orientations of crops. Agric. Meteorol., 53(1): 2-39.

Champan, S.R. and Carter, L.P. 1976. Crop production principles and practices. W.H. Freman and Company, San Francisco. p. 566.

Chin Choy, E.W. and Kanemasu, E.T. 1974. Energy balance comparisons of widea and narrow row spacing in sorghum. Agron. J., 66: 98100 .

Fritschen, L. J. and Van Bavel, C.H.M. 1962. Energy balance components of evaporative surfaces in arid lands. H. Geophys. Res., 67: 51795185 .

Ham, J.M.; Heilman, J.L. and Laseanao, R.J. 1991. Soil and canopy energy balances of a row crop at partial cover. Agron. J., 83: 744-753.

Hammer, D.A. 1989. Constructed wetlands for Wastewater Treatment, Municipal, Industrial and Agricultural. Lewis Publishers Inc. Boca Raton, FL, USA. pp. 151-153.

Kler, D.S.; Kaur, H. and Singh, S. 1992. Effect of bidrectional sowing and nitrogen on microclimate and yield of Indian rape Brassica campestris L. Va Tori. Environment and Ecology, 10(2): 282-291.
Parkhurst, R.S.; Winter, T.C.; Rogenberry, D.O. and Sturrock, A. 1998. Evaporation from a small prairie wetland in the cottonwood lake area, North Dakota-an energy budget study. Wetlands, 18: 272-287.

Rao, A.S. 1988. Evapotranspiration rates Eichhornia crasssipes (Mart.) Solms, Salvinia molesta D.S Mitchess and Nymphaea lotus (L) Wild. Linn. In a humid tropical climate. Aqu. Bot., 30: 215-222.

Sakuratani, T. 1987. Studies of evapotranspiration from crops and separate estimation of transpiration and evaporation from a soybean field without water shortage. $J$. Agric. Meteorol. Jph., 42: 309-317.

Schou, J.B.; Jeffers, D.L. and Streeter, J.G. 1978. Effect of reflectors, blackboards or shades applied at different stages of plant development on yield of soybeans. Crop Sci., 18: 29-34.

Szlovak, S.; Szabo, T. and Koos, L. 1992. Studies on the correlation between canopy temperature of maize stand and water supply of plants. Res. Inst., Szarvas, Hungary. In Proc. $16^{\text {th }}$ ICID European Vol. 1. Drought Phenomena. pp. 479-489. 